\title{
Biologization technologies in agriculture of the Belgorod region
}

\author{
N.I. Kloster, and V.B. Azarov* \\ FSBEI HE Belgorod State Agrarian University, Belgorod, Russia
}

\begin{abstract}
The article summarizes the results of field experiments to study the effectiveness of biologization elements in the cultivation of agricultural crops in the Central Black Earth zone of Russia. It has been proved that compost based on poultry manure and granular organic fertilizers with shallow introduction contribute to an increase in yield of up to $50 \mathrm{cwt} / \mathrm{ha}$ of grain while improving the fertility of typical chernozem. The coefficient of structure is growing, the bulk density of the soil, physical and chemical characteristics are stabilized. Liquid pig-breeding drainage shows an increase in grain yield but does not have a significant effect on the state of arable land. Similar characteristics apply to technologies for the grain crops cultivation with the use of mineral fertilizers. The greatest economic efficiency was obtained with the combined application of different types of organic fertilizers in moderate doses with the surface method of the main soil cultivation.
\end{abstract}

\section{Introduction}

The Belgorod Region is one of the most developed agrarian regions of the Russian Federation. With about $1 \%$ of the country's arable land and $1 \%$ of the population, the region produces more than $20 \%$ of all Russian meat, $15 \%$ of sunflower seed oil and mayonnaise, and is second only to the Krasnodar Krai in terms of yields of major grain crops [1]. These achievements were the result of the regional government policy, which outlined strategic priorities such as maintaining state control over agricultural land, general ecologization of the agro-industrial complex, maximum use of animal husbandry waste as fertilizer and the use of energy-saving soil cultivation [4].

Due to the irrational use of natural resources, the chernozems of the Belgorod region have lost a significant part of their fertility during their agricultural use [3]. These trends are typical not only for many regions of Russia, but also for developed Western countries. The solution to this problem can be the transfer of agriculture to a biological basis, in which high stable yields of agricultural crops would be combined with the preservation and reproduction of soil fertility [7].

However, the development of agricultural technologies that include biologization elements requires detailed study and experimental verification in the field. For the most reliable assessment of these factors, it is essential to establish field experiments using

\footnotetext{
* Corresponding author: azarov.vb@mail.ru
} 
scientifically grounded methods with a comprehensive study of the proposed options for their influence not only on the productivity of cultivated crops, but also on the general state of the exploited lands' fertility. Such experiments, including the factors like the use of innovative organic fertilizers, methods of tillage and various grain crops, have not been carried out in the conditions of the Central Black Earth Region of Russia. Therefore, such studies are relevant and novel and will be extremely useful to agricultural production.

\section{Materials and methods}

In the light of the above, a field experiment in the Rakityansky district of the Belgorod region was established, where, according to a scientifically grounded method, various factors of agricultural technologies' biologization were studied in the cultivation of basic grain crops.

The experiment used a typical crop rotation with alternating crops used in most farms that provide the livestock industry with a full-fledged fodder base. The crop rotation was three-field grain including soybeans, winter wheat and corn for grain.

According to the method of field experiment [2], the repetition was threefold, the experiment is located in time and space. In nature, there are three fields annually with a full range of crops. The area of an elementary plot is $100 \mathrm{~m}^{2}(4 \times 25 \mathrm{~m})$. There are protective corridors between the blocks of plots to exclude the mutual influence of factors and the passage convenience of agricultural machinery.

The purpose of the field experiment was to determine the effect of compost based on poultry (chicken) manure and pig-farming drainage on the yield of the main grain crop corn, and the quality indicators of typical chernozem's fertility in comparison with the traditional mineral fertilization system.

The options of the field experiment were selected considering the possibility of comparing the obtained experimental data and corresponded to the principle of single difference. For nine fertilization gradations, which fully reveal the goals and objectives of the research, two methods of fertilizer's placement were superimposed:

1. Deep mouldboard with fertilizers' placement at $25 \mathrm{~cm}$;

2. Surface tillage with fertilizer's placement to a depth of no more than $10-15 \mathrm{~cm}$.

The main emphasis when choosing the plots' filling with fertilizers was the need to check the local organic fertilizers' efficiency.

Options under study:

1. Control without the use of fertilizers

2. Mineral fertilizers full dose in autumn

3. Pig-breeding effluents full dose in autumn

4. Pig-breeding effluents with the division of the full dose in equal shares in autumn and spring before sowing

5. Compost based on poultry manure full dose in autumn

6. Mineral fertilizers half dose in autumn

7. Pig-breeding effluents half dose in autumn

8. Compost based on poultry manure half dose in autumn

9. Pig-breeding effluents half dose + compost half dose in autumn

The full dose of fertilizers was calculated for the planned corn yield of $120 \mathrm{cwt} / \mathrm{ha}$ in nitrogen terms.

The records, observations and analyzes were carried out according to the methods generally accepted in agriculture and agrochemistry in accordance with GOSTs. 


\section{Results and discussion}

For the favorable growth and development of agricultural crops, it is necessary to comply with several conditions regarding the quality indicators of the cultivated soil. On the chernozem soils of the Central BEZ, the main limiting factors include agrophysical properties, the main of which are the structural coefficient and the bulk density [8]. In the experiments, these indicators were determined for all experimental options using modern materials in accordance with approved methods.

As a result of the studies, it was revealed that the structural coefficient for all experimental options was within the optimal values, which allows to conclude that the typical chernozem has good agrophysical properties, which is characterized by the predominance of a nuciform-cloddy structure.

As shown by the records and observations results, among the factors influencing the structural characteristics of typical chernozem, options with the use of compost based on chicken manure in various doses and combinations can be distinguished. This fertilizer is a solid substance of a loose consistency saturated with coarse organic matter and impregnated with a nutrient mixture of various nitrogen compounds. It is obtained by composting fresh manure with finely chopped straw, cormophyte corn mass and other residues of plant origin. The fertilizer is concentrated with a predominance of nitrogen in plant-available forms. The total nitrogen content was $2.5-3 \%$. The positive effect of this fertilizer on the soil structure can be explained by the significant loosening of the soil root layer when introducing compost. Other fertilizer's types such as pig-breeding effluents and mineral fertilizers did not significantly affect the soil structure. Analyzing the data on the change in the structural coefficient depending on the tillage, it is possible to state a certain excess of this indicator's value in deep plowing, especially in the subsoil horizon.

Corn is a very demanding crop in terms of good soil aeration, which is ensured by such an important agrophysical indicator as soil density. With excessive density, the growth and development of the root system is inhibited, the access of atmospheric oxygen to the root zone is complicated. Corn actively develops ground or amino acid roots at the critical stage of the growing season, which participate in the additional supply of nutrients to the generative organs and the formation of grain swelling; for it, this indicator acquires special significance.

Another important indicator of soil well-being is its density determined by the wellknown formula as the ratio of mass to volume; in chernozem soils under favorable conditions, it amounts to $1.0-1.2 \mathrm{~g} / \mathrm{cm}^{3}$. This interval is considered to be optimal for the cultivation of most agricultural crops in the region.

According to the research program, this indicator was determined in the middle of the growing season of the studied crop - corn for grain - by plots in a row by selecting a whole monolith of a known volume with further weighing and making appropriate calculations.

Our research led to conclusions about the favorable agrophysical properties of the soil of the experimental site. Depending on the method of soil cultivation and the fertilization level, the soil density was in the range of $1.08-1.19 \mathrm{~g} / \mathrm{cm}^{3}$ with large values at control without fertilizers and with a mineral system in the lower soil layer and with surface cultivation. The minimum density values were noted when introducing compost with deep cultivation in a $0-20 \mathrm{~cm}$ soil layer.

The regularity of soil density decreases from the use of solid organic fertilizers, which is organic compost, is explained by mixing the bulk of the fertilizer product with the soil, an increase in the number of air pores, voids, and a decrease in soil mass at the initial volume. The bulk soil mass obtained in this option within the range of $1.10-1.13 \mathrm{~g} / \mathrm{cm}^{3}$ contributes to the full development of the corn root system and ultimately allows to show productivity close to biologically potential one. 
Since the main goal of this research was to determine the local organic fertilizers' efficiency, authors considered it necessary to include the study of the soil biological activity in the experimental program as an important indicator that can show how much the soil is able to process the nutrients of the introduced organic matter and convert them into a form accessible to plants, which is the ultimate purpose of any fertilizer.

According to the existing methodology, linen laying of the nominal weight was carried out on all experimental plots in two soil horizons with a monthly explication. According to the decomposition intensity of the tissue sample, the biological activity of the soil was determined in $\%$ of decomposition.

Represented in most fields in the southwestern part of the Central Black Earth region of Russia, typical chernozems have high potential biological activity due to the rich set of soil biota. This postulate was confirmed in our experiment, where even on options with a fertilizer application dose equal to zero, the degree of linen decomposition reached a value of $14.5-16.2 \%$ with large values for surface tillage.

The mineral fertilizer system considered as an object of comparison with the main experimental factors - organic fertilizers - did not show significant differences from unfertilized options, since mineral fats are not able to provide soil biota with material for nutrition and processing without an organic component in its composition. On these plots, the soil bioactivity index was $14.3-15.9 \%$.

Pig-breeding effluents, which are an almost completely liquid fraction, changed the biological activity of the soil upward by an insignificant amount of about 3-3.5\%. In this case, it can be assumed that the additional nutrition of soil bacteria was taken from the nitrogenous components of the fertilizer, which reduced the fertilizing value of the pigbreeding effluents. Compost based on poultry manure was the most productive from the point of view of the biological activity of the soil, especially in combination with pigbreeding effluents in half application doses. The percentage of linen decomposition in the soil layer of $0-20 \mathrm{~cm}$ on these plots amounted to $22-28$. Attention is drawn to the tendency of the dependence of biological activity level on the fertilizer's introduction depth. So, a higher level was recorded in the upper soil layer with surface tillage, and for deep mouldboard plowing this value was practically equal for all studied layers.

When cultivating crops with the formation of large vegetative mass and significant productivity including corn, which is cultivated for the purpose of obtaining grain, it is of particular importance to provide the soil with a sufficient amount of basic nutrients, the main of which is nitrogen in the Central Black Earth region of Russia. Moreover, the provision of this element for corn is important during critical consumption periods. That is why it was considered expedient to trace the dynamics of the soil supply with mineral nitrogen in several periods: before the autumn fertilizers' introduction, before sowing and during the critical periods of the growing season. For ease of comparison, the conversion of the nitrogen content in the soil into its reserves was carried out using mathematical calculations and considering the indicators of soil density in different layers and fertilization options.

The research results show that in autumn nitrogen reserves in the experimental field did not differ by plots and amounted to 57 to $85 \mathrm{~kg} / \mathrm{ha}$ in the upper $20-\mathrm{cm}$ soil layer and from 49 to $77 \mathrm{~kg} / \mathrm{ha}$ in the lower soil profile.

Experimental data on the dynamics of mineral nitrogen during corn growing season are of practical interest. Analyzing the data on the option without the use of fertilizers, it can be concluded that there was an increase in the amount of nitrogen in the spring before sowing, especially in the upper soil horizon. An explanation for this fact should be sought in the intensive mineralization of a part of straw, chaff, root residues and other parts of plants of preceding winter wheat in the presence of significant activity of cellulose-decomposing microorganisms in the soil. Nitrogen reserves in the control naturally decrease with the 
beginning of corn growing season, reaching values less than $50 \mathrm{~kg} / \mathrm{ha}$ at the third sampling, which is undoubtedly an insufficient level to obtain full grain productivity.

Being the most mobile fertilizing substance, mineral fertilizers including water-soluble nitrogen compounds showed a significant excess of spring mineral nitrogen reserves in the soil over autumn ones. On plots with surface tillage, the nitrogen content in the lower layers was $187 \mathrm{~kg} / \mathrm{ha}$. This fact raises certain concerns, since a soil layer of $20-40 \mathrm{~cm}$ is not a fertilizers' introduction location but serves as a conductor for mobile nitrogen compounds into the underlying soil layers. With high doses of mineral fertilizers and with sufficient moisture supply, it is possible to wash out nitrates into deep soil horizons, which creates preconditions for groundwater pollution and disturbance of the ecological balance.

Further, there is an intensive consumption by corn plants against the mineral background and, possibly, the transformation of nitrogen into the lower layers. To verify this thesis, deep drilling and work with special nitrogen markers are required.

Pig-breeding effluents introduced in the fall at a full fertilizing dose showed values even slightly lower than in the autumn period during the spring pre-sowing soil sampling. However, the indicator of the plants' supply with mineral nitrogen increased to values of $125-140 \mathrm{~kg} / \mathrm{ha}$ during the growing season. In this case, we are probably dealing with pulling up dissolved nitrogen with upward currents of soil moisture into the root layers of the soil.

From the point of view of reducing production costs and freeing up storage sites for organic matter, the option with fractional introduction of pig-breeding effluents is of particular interest. Under this scheme, the reserves of mineral nitrogen decrease in the upper layer before sowing; then in June they slightly increase to $90 \mathrm{~kg} / \mathrm{ha}$ and further to 138 $\mathrm{kg} / \mathrm{ha}$ as the organic nutrients are processed and the nitrogen of the soil solution passes from the lower layers. On the contrary, large reserves of nitrogen were noted in August in the $20-40 \mathrm{~cm}$ soil layer. In general, the reserves of mineral nitrogen were at a fairly high level in this option.

In the options where the experimental scheme provided for the compost use based on poultry manure in the upper soil layer, the maximum recorded nitrogen reserves were at $136 \mathrm{~kg} / \mathrm{ha}$. By all means, most of the nitrogen in the compost is in the ammonium form, for which the exchange absorption by the soil-absorbing complex is typical. Thus, the spatial mobility of this given form of nitrogen is much lower than the nitrate one, which is capable of transforming with descending and ascending currents far along the soil profile passing into the soil solution. According to the observations results, it is the ammonium form of nitrogen that is the best for the growth and development of corn plants. This fact is confirmed by the data on mineral nitrogen reserves in the soil layer up to $40 \mathrm{~cm}$, where in April the difference in values with the upper layer was $74 \mathrm{~kg} / \mathrm{ha}$, that is, two times less. In the process of nitrogen usage by plants, its reserves are reduced amounting to 75 and 60 $\mathrm{kg} / \mathrm{ha}$ at the third sampling in the upper and lower soil layers, respectively.

Options with full doses of fertilizers calculated for the planned corn grain yield of 120 $\mathrm{cwt} / \mathrm{ha}$ are in some cases excessive and, according to several scientists $[3,6]$, need to be adjusted. Options with half doses of fertilizers were introduced into the experimental scheme for this purpose.

When studying the dynamics of mineral nitrogen reserves in the soil, it can be stated that the above-mentioned regularities persist as with full doses of all types of fertilizers. So, with a reduced NPK dose with surface tillage in autumn, the nitrogen content in the upper layer increases in spring by $27 \mathrm{~kg} / \mathrm{ha}$ and by $46 \mathrm{~kg} / \mathrm{ha}$ in the $20-40 \mathrm{~cm}$ layer, and in absolute values, the lower layer was much richer in mineral nitrogen than the top.

The option with the simultaneous introduction of two organic fertilizer types - compost and pig-breeding effluents at a $1 / 2$ dose - is also of economic importance. Here a stable increase in mineral nitrogen concentration in the soil is recorded precisely in the $0-20 \mathrm{~cm}$ 
layer. In the spring before sowing, nitrogen reserves were at the level of $106 \mathrm{~kg} / \mathrm{ha}$, in Juneearly August they increased to 127 and $141 \mathrm{~kg} / \mathrm{ha}$, respectively. In the lower layer, the maximum value was noted in the spring $-127 \mathrm{~kg} / \mathrm{ha}$, then there was a decrease in nitrogen reserves. In these options, the value of compost should be considered as an organic absorbent that accumulates nitrogen compounds from pig-breeding effluents at the place of introduction creating an increased concentration gradient. This process takes place in JuneAugust with a gradual release of nutrients due to constant mineralization for the consumption by corn plants, which allows not only to form an optimal nitrogen soil regime, but also increases its agrophysical properties and the activity of soil microorganisms.

High concentrations of soil mineral nitrogen were recorded during the joint application of poultry compost and pig-breeding effluents at the second and third sampling periods along the entire soil profile. Nevertheless, in early August, the reserves of mineral nitrogen in these options significantly decreased to values of $67-81 \mathrm{~kg} / \mathrm{ha}$. This pattern was also noted for other fertilized options with deep soil cultivation.

Analyzing the change in mineral nitrogen reserves in the chernozem of the experimental field overall, one should note their high variability both in fertilization and in the soil profile. Possessing a high absorption capacity, good structure and high biological activity, chernozems can convert nitrogen compounds of both fertilizers and soil reserves into various compounds. The processes of mineralization, humification of nitrogen complex substances go on continuously, changing their direction depending on many factors. When building a system for fertilizing grain crops, it is necessary to consider the dynamics of the soil nitrogen fund and make appropriate adjustments.

The high culture of agriculture on the farm, the optimal system of plant protection from pests and diseases made it possible to obtain the yield of corn at the level of 44.3-58.6 cwt/ha even on control without fertilizers. Mineral fertilizers showed an increase from the full dose of 28-31 cwt/ha, from the reduced dose - 21-25 cwt/ha, i.e., those applied for the planned harvest did not show the expected efficiency.

Organic fertilizers have shown different efficiency in terms of their effect on grain yield.

Both pig-breeding effluents and organic compost were effective in corn cultivation. If the increase value from liquid organic matter fluctuated within $85-95 \mathrm{cwt} / \mathrm{ha}$, then it increased to $100-115 \mathrm{cwt} /$ ha from solid fertilizers (compost) - almost equal to the calculated values.

Attention is drawn to the fact of high efficiency of half organic matter norms - at the level of 76 in the option with effluents and up to $100 \mathrm{cwt} /$ ha with compost (Table 1).

The maximum yield was recorded with the combined half doses application of compost and pig-breeding effluents - $122.1 \mathrm{cwt} / \mathrm{ha}$. It seems that these fertilizers successfully complement each other in terms of creating conditions for expanded soil reproduction and the formation of a full corn grain yield.

Table 1. Productivity of grain corn against the background

of biologization techniques usage, (cwt/ha), 2016-2018.

\begin{tabular}{|c|c|c|c|c|c|c|c|c|c|}
\hline Fertilizer & $1^{*}$ & 2 & 3 & 4 & 5 & 6 & 7 & 8 & 9 \\
\hline Surface & 58.6 & 89.6 & 96.2 & 113.7 & 116.8 & 80.4 & 76.1 & 97.7 & 122.1 \\
\hline Plowing & 44.3 & 73.1 & 84.3 & 91.4 & 101.4 & 69.4 & 71.8 & 79.8 & 109.4 \\
\hline LSD $_{05}$ & \multicolumn{7}{|c|}{5.9} \\
\hline
\end{tabular}

* - the content of the experimental options in the scheme at the beginning of the article

Any agricultural activity provides for obtaining maximum possible profit for producers. Therefore, the economic efficiency calculation of the studied agricultural technologies was included in the research program. 
Mineral fertilizers with equal efficiency of full and half doses showed a total profit of 14-17 thousand rubles/ha with a profitability level of $21-24 \%$.

Organic fertilizers in the form of pig-breeding effluents increased the profitability of corn production to $50-76 \%$, provided that the full dose was applied. Compost based on chicken manure made it possible to obtain a net profit from the full dose of 51 thousand rubles/ha and 35 thousand from the half dose.

The best option for efficiency turned out to be the combined application of compost and liquid effluents from pig farms. In this case, the profit amounted to 57,000 rubles/ha with a profitability of 87 percent.

\section{Conclusions}

Such agrophysical properties as the structural coefficient and soil density differed in optimal values for almost all options of the experiment with a predominance of options with solid organic fertilizers. The biological activity was higher when using compost, while the efficiency of the main soil cultivation methods was practically equal.

With the surface soil cultivation method, the nitrogen reserves in the soil were maximum when introducing the full dose of organic compost with a predominance of values in the upper $20 \mathrm{~cm}$ soil layer. Against the background of deep mouldboard cultivation, the plants were best supplied with nitrogen when introducing compost based on poultry manure together with pig-breeding effluents with a higher concentration of mineral nitrogen in the lower soil layer up to $40 \mathrm{~cm}$.

The highest corn yield was recorded with the combined use of pig-breeding effluents and poultry compost - $122.1 \mathrm{cwt} / \mathrm{ha}$ with a surface tillage method.

The best economic efficiency of grain corn cultivation was noted with the introduction of a full compost dose, as well as fractional application of pig-breeding effluents and the combined application of different types of organic fertilizers in half doses. In this case, the profitability level of agricultural production was 76-87 percent.

\section{References}

1. Report of the Governor of the Belgorod Region to the Government of the region "On the results of 2019", Newspaper "Belgorodskaya Pravda" (2020)

2. B.A. Dospekhov, Field experiment method (with the basics of statistical processing of research results), 351 (1985)

3. S.V. Lukin, Ecological foundations of agriculture, 288 (2006)

4. Decree of the Government of the Belgorod Region No. 14-PP dated January 26, 2015 "On the introduction of a biological farming system"

5. I.G. Pykhtin, A.V. Gostev, Theoretical foundations for the use of zero and surface methods of basic soil cultivation for grain crops, Information and technological support of adaptive landscape farming systems, 241-246 (2012)

6. V.Ya. Rodionov, N.I. Kloster, Fertilizers in modern agriculture, 213 (2013)

7. A.V. Turyansky et al., Technological regulations for the cultivation of major agricultural crops in the Belgorod region, 687 (2012)

8. E.G. Kotlyarova, IOP Conference Series: Earth and Environmental Science, 624, 012228 (2021) (Scopus \& WoS) doi:10.1088/1755-1315/624/1/012228 